\title{
CURRICULUM INTEGRATION FOR MEDICAL AND DENTAL STUDENTS
}

\author{
Rajeshwar Reddy Kasarla, ${ }^{1}$ Laxmi Pathak ${ }^{2}$
}

\begin{abstract}
Many medical and dental colleges have been following a traditional curriculum which is characterized by a discipline/subject wise model, with high degree of division of different subjects into pre-clinical, para-clinical, and clinical branches, without any correlation between the different subjects and topics. As a result, the knowledge gained by students becomes irretrievable and inadequate to apply in clinical situations. Lack of integrated approach to different subjects, during learning period, results in bringing out medical graduates lacking holistic approach toward the patients and the community while practicing medicine. Therefore, there is a need for a revision in medical education, not only in terms of the changes in our knowledge base, but also in terms of the regarding patients, medical practitioners and society in general. Integrated curriculum seeks to break down the barriers between the subject areas i.e., basic and clinical sciences, in order to promote acquisition, retention, and progressive development of knowledge and skills, and facilitate applications of principles and concepts to understand problems and develop problem solving skills. It views learning and teaching in a holistic way and reflects the real world, which is interactive, and helps students to apply their knowledge to their work and to their personal development. This article pertaining to the discipline of medical education makes an attempt to review and discuss the various types of curriculum and its integration for MBBS and BDS students.
\end{abstract}

\section{KEYWORDS}

Curriculum, Horizontal integration, Spiral integration, Vertical integration.

1. Department of Microbiology, Universal College of Medical Sciences, Bhairahawa, Nepal

2. Department of Anaesthesiology and Critical Care Medicine, Universal College of Medical Sciences, Bhairahawa, Nepal

DOI: http//doi.org/10.3126/ jucms.v9i01.37989

For Correspondence

Dr. K. Rajeshwar Reddy

Microbiology Department

Universal College of Medical Sciences

Bhairahawa, Nepal

Email: reddysir4861@gmail.com 


\section{INTRODUCTION}

The curriculum is a system of learning experiences and opportunities that are planned for students through their education. Curriculum is the vehicle through which a country empowers its citizens with the necessary knowledge, skills, attitudes, and values that enable them to be socially and economically engaged and empowered, for personal and national development. Curriculum should, therefore, meet the needs of the individual citizens and the nation. ${ }^{1}$

Many medical and dental colleges around the world have been following a traditional curriculum which is characterized by a subject wise model, with high degree of division of different subjects into pre-clinical, para-clinical, and clinical branches. The traditional curriculum is subject based, teacher centered, examination oriented, where in learners are presented with a series of subjects or topics in isolation. Students often fail to get a comprehensive knowledge of the subjects, and the relevance of the various subjects is not appreciated, and the knowledge gained is inadequate for clinical application. The relevance of the basic sciences subjects is not understood in the first two years of MBBS and BDS programs, resulting in lack of motivation and interest in studies. Traditional teaching drives learning into an intensive examination-oriented manner with an aim to just pass the examinations, rather than an attempt to grasp the subjects in a comprehensive manner.

Curriculum for MBBS and BDS students is very extensive and students are expected to learn many subjects at the same time, and provides knowledge to the students in an unbalanced and disproportionate manner. Students absorb information passively rather than actively. Students will not develop critical thinking, problem-solving, and decision making skills to investigate, diagnose, and treat the patient as a whole. ${ }^{2}$

Medical education continues to change in response to rapidly expanding scientific knowledge, technological advancements and innovations, social needs, and aspirations of young doctors. Thus, there is a need for a revision in medical education, not only in terms of the changes in our knowledge base, but also in terms of the regarding patients, medical practitioners and society in general.

\section{TYPES OF CURRICULUM}

Medical colleges across the world have been using different models of curricula for MBBS and BDS programs, which include traditional discipline-based curriculum, integrated curriculum, organ-based curriculum, competency based curriculum, problem based learning curriculum, case based learning curriculum and community based curriculum. Each curriculum has its own advantages and disadvantages. ${ }^{4}$

\section{Organ based curriculum}

Organ based curriculum is the curriculum where medical education runs according to each organ system with both horizontal integration and vertical integration. Organ-based curriculum is one of the most popular curricula for undergraduate medical education in America and in very few Caribbean medical colleges. ${ }^{5}$

\section{Competency based curriculum}

Competency based medical curriculum is one of the recent designs of the curriculum. It is introduced in Indian medical colleges from August 2019 by Medical Council of India. It differs from other non-related approaches in that the unit of learning is extremely fine-grained. Competency based learning is an approach to teaching and learning, used in learning concrete skills than abstract learning. Rather than a course or topic or a module, every individual skill or learning outcome (known as a competency) is one single unit. Learners work on one competency at a time, which is likely a small component of a larger learning goal. The student is evaluated on the individual competency and can only move on to other competencies after they have mastered the current skill being learned. After that, higher or more complex competencies are learned to a degree of mastery and are isolated from other topics. Another common component of competency-based learning is the ability to skip learning modules entirely if the learner can demonstrate mastery, determined through prior learning assessment or formative testing. ${ }^{6}$

\section{Community based curriculum}

The other approach in undergraduate medical education is community based curriculum where a community approach is of primary importance. Community-based education involves learning activities that take place in a community setting. Community-based education is now recognized as an important addition to medical education, because the skills of graduates are needed more in communities than in urban and tertiary hospitals. Community-based education may promote socio-behavioral aspects of medical students in understanding factors affecting health problems in daily contexts.

\section{Problem based learning (PBL) curriculum}

PBL is an instructional student-centered pedagogy which uses carefully constructed clinical problems as a context for students to define their learning needs, conduct self-directed enquiry, integrate theory and practice, and apply knowledge and skills to develop a solution to a defined problem, and teacher serving as facilitator of learning. It enhances critical appraisal, literature retrieval and encourages ongoing learning within a team environment. 


\section{Case based learning (CBL) curriculum}

Case based learning is a newer modality of teaching using human cases to impart relevance, and prepare students for clinical practice, through the use of authentic clinical cases. It links theory to practice, through the application of knowledge to the cases, using inquiry-based learning methods. ${ }^{9}$

\section{Traditional discipline-based curriculum}

In traditional discipline-based curriculum, students are not exposed to clinical education or patients until the third year of their MBBS or BDS. During the first two years of their MBBS or BDS, the curriculum is completely focused on basic sciences. Moreover, in traditional approach of the curriculum, there is no correlation between the different subjects and topics. As a result, the knowledge gained by students becomes irretrievable and inadequate to apply in clinical situations. Lack of integrated approach to the different subjects, during learning period, results in bringing out medical and dental graduates lacking holistic approach toward the patients and the community while practicing medicine. ${ }^{10}$

\section{Hidden curriculum}

In all types of curricula, there is hidden curriculum, which is a side effect of education (which are learned), such as the transmission of norms, values, and beliefs conveyed in the classroom and the social environment. ${ }^{13}$

\section{CURRICULUMINTEGRATION}

There is a famous saying that, "Knowledge that is learnt in isolation is rapidly forgotten". The dictionary meaning of integration is "to make entire". Integration is defined as the organization of teaching matter to interrelate or unify the subjects which are frequently taught in separate subjects or departments. ${ }^{5}$ Integrated curriculum seeks to break down the barriers between the subject areas i.e., basic and clinical sciences (Interdisciplinary curriculum), in order to promote acquisition, retention, and progressive development of knowledge and skills, and facilitate applications of principles and concepts to understand problems and develop problem solving skills. ${ }^{11,12,14,15}$

The time available for the MBBS and BDS subjects needs to be effectively and efficiently managed.Vast amounts of information can be delivered in a concise, comprehensive, and meaningful manner by integrated approach to the curriculum. In medical education, basic sciences details are difficult to connect to clinical scenarios for novice students with limited or no clinical exposure; this challenge is overcome by linking basic sciences matter to clinical problems, often through integration. Integration of curriculum also enhances interest, stimulates intellectual curiosity and enriches student learning. Medical and dental colleges around the world are moving from the traditional discipline-oriented curriculum to an integrated curriculum. ${ }^{11}$

Ideally, integration should commence after a period of initial instruction in some basic and general concepts, especially in basic sciences. Students at entry level may not be equipped with the necessary skills required for effective knowledge integration and self-directed learning. A guided approach in the first year of MBBS and BDS might help them develop into successful independent learners. It requires a certain level of cognitive maturity to understand, harmonize, and apply the knowledge in a meaningful way. ${ }^{12}$

Harden postulated that curricular integration can be viewed as a ladder (Integration Ladder) and suggested 11 sequential steps, with subject-based teaching (isolation) at the bottom of the ladder and full integration (trans-disciplinary teaching) at the top. Harden provides descriptions of each step on the ladder and makes clear distinctions between the progressive integration from one step to the next. As one moves up the ladder, there is less emphasis on the role of disciplines/ subjects, an increasing requirement for a central curriculum, organizational structure and a requirement for greater participation by staff in curriculum discussions and planning (Fig 1). The integration ladder is a useful tool for the medical teacher in planning, implementing and evaluating the medical curriculum. $^{12,16}$

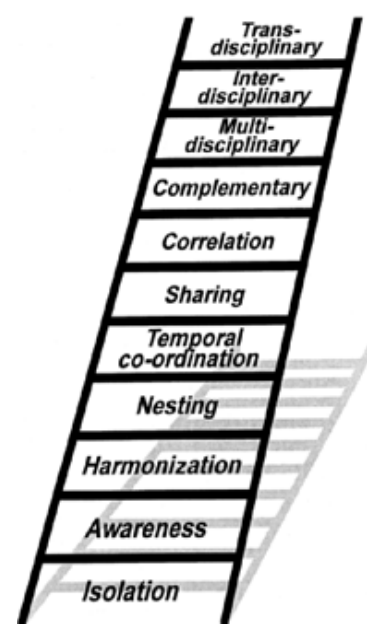

Fig 1. Eleven sequential steps of Harden's integration ladder

\section{TYPES OF INTEGRATION}

There are many versions of integration ${ }^{5}$ and any one of a number of combinations between the basic sciences and the clinical subjects may be adopted: 1 . Horizontal integration, 2. Vertical integration, and 3. Spiral integration. 


\section{Horizontal integration}

Horizontal integration is defined as integration between the basic sciences subjects or between the clinical sciences subjects. Horizontal integration brings together the disciplines, topics, and subjects (Fig 2). In Nepal at Tribhuvan University, organ based curriculum with horizontal integration between basic science subjects (anatomy, physiology, biochemistry, microbiology, pathology, pharmacology), with early clinical and community exposure is being implemented. Students in the pre-clinical years learn each organ system, moving from one organ to the next over a two-year time span. ${ }^{17,18,19}$

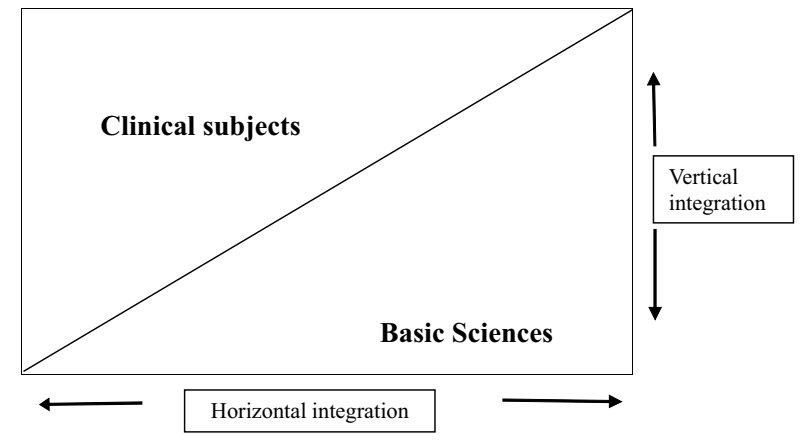

Fig 2. Horizontal and vertical integration

\section{Vertical integration}

Vertical integration in a curriculum means that basic sciences are integrated with clinical sciences, in such a way that the traditional divide between the pre-clinical and clinical sciences is broken down. Vertical curriculum links knowledge from one subject topic to the next across a program of study. It establishes skills and knowledge (basic skills, clinical skills, diagnostic reasoning, differential diagnoses and management options) which are used and further developed across a whole program (MBBS or BDS) of study (Fig 2). It bridges the gaps between theory and practice, and hospital based medicine and community medicine. ${ }^{19,20}$

\section{Spiral integration}

A spiral curriculum is one in which there is revisiting of topics, subjects or themes throughout the MBBS or BDS program repeatedly. The topics visited are addressed in increasing levels of difficulty. Each return visit can bring new knowledge or skills related to topic, related to previous learning. The learner's competence increases progressively with each visit. ${ }^{21}$

In a spiral integrated curriculum model at the University of Dundee, Dundee, UK, the basic and clinical sciences are continually integrated as students' progress from learning the "normal" to the "abnormal" before the clinical portion of their education. At the top of the cone are three domains of learning - cognition (knowledge), skills, and attitudes, that are a focus of all levels of the spiral. Additional themes such as clinical methods, ethics, and health promotion persist throughout all years (Fig 3$)^{21}$

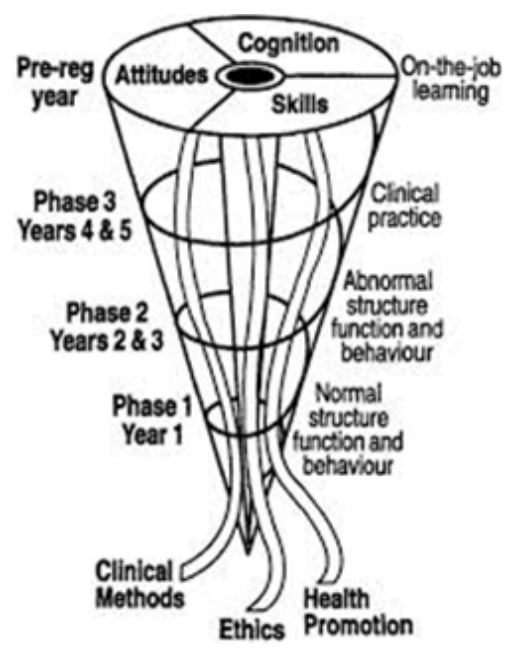

Fig 3. Spiral integrated curriculum model at the University of Dundee, UK

\section{CONCLUSION}

Integrated teaching is more effective than traditional teaching; provides correlation between the various subjects, enabling the students to grasp medicine in its entirety. During basic sciences, integration brings relevance to the subjects taught, thereby increasing interest in the subjects. Better correlation among the subjects results in better comprehension and in turn better performance by the students. It improves their insight into the subjects, provides better outlook toward the management of clinical conditions, and enables them to have a holistic approach to the patients. Implementation of integration in a curriculum is a demanding task that requires effective leadership at the program level, collaborative effort from faculty members, administrative support from staff, and cooperation from students.

\section{ACKNOWLEDGMENT}

We acknowledge and profusely thank all those legend writers of Medical Education who inspired us to write this review, particularly Dr. Ronald M. Harden, and we have liberally borrowed some information and figures from some famous articles in Medical Education. We thank Ms. (Dr.) Aishwarya Verma, MBBS student, Universal College of Medical Sciences, Bhairahawa, Nepal for evincing keen interest and helping us in obtaining literature, as the information pertaining to this topic was very limited. 


\section{REFERENCES}

1. Berliner DC. Redesigning classroom activities for the future. Educational Technology. 1992;32(5):7-13.

2. Doraiswamy R, Radhakrishnan S. The effectiveness of integrated teaching over traditional teaching among first year MBBS students: A preliminary study. Med J DY Patil Univ. 2013 ;6:139-141.

3. Smith SR. Toward an integrated curriculum. Med Health R I. 2005;88(8):258-261.

4. Reddy KR. Challenges in conducting MBBS program in a Nepalese Medical College. J-GMC-N. 2017;10(1):49-56.

5. Reddy KR. Correlation seminars in basic sciences at Gandaki Medical College, Lekhnath, Kaski, Nepal. J-GMC-N. 2016;9 (1):57-61.

6. Harris P, Snell L, Talbot M, Harden RM. Competency based medical education: implications for undergraduate programs. Med Teach. 2010;32(8): 646-650.

7. Mennin S, Petroni-Mennin R. Community based medical education. The Clinical Teacher. May 2006;3:90-96.

8. Wood F. ABC of learning and teaching in medicine: Problem based learning. British Medical Journal. 2003;326:328-330.

9. McLean SF. Case-based learning and its application in medical and health-care fields: A review of worldwide literature. J Med Educ Curric Dev. 2016;3:JMECD.S20377.

10. Amudha Kadrivelu, Sunil Gurtu. Integrated learning in medical education: Are our students ready? Medical Science Educator. Dec 2015;25(4):549-551.

11. Bandiera G, Boucher A, Neville A, Kuper A. Integration and timing of basic and clinical sciences education. Medical Teacher. 2013;35(5):381-387.

12. Brauer DG, Ferguson KJ. The integrated curriculum in medical education: AMEE Guide No. 96. Medical Teacher. 2015;37:312322 .

13. Rajput V, Mookerjee A, Cagande C. The contemporary hidden curriculum in medical education. MedEdPublish. 2017;6(3):41.

14. Varsha Shah, Uresh J Jain. The effectiveness of integrated teaching over traditional teaching in third MBBS students. International Journal of Medical science and Public Health. 2016 ;5(7):1430-1432.

15. Magoma CM. The shift and emphasis towards curriculum integration: Meaning and rationale. African Educational Research Journal. April 2016;4(2):25-30.
16. Harden RM. The integration ladder: a tool for curriculum planning and evaluation. Medical Education. $2000 \mathrm{Jul} ; 34(7)$ : 551-557.

17. Gaddam VL, Gowda V, Vaidyanathan K. Comparison of the effectiveness of horizontal integration with traditional teaching approach in first-year MBBS students. International Journal of Medical Science and Public Health. 2016;5(7):1360-1363.

18. Sharma S, Kacker S, Jha M. Effectiveness of horizontal integrated teaching program in medical curriculum. Int J Pharm Sci Res (IJPSR). 2015;6(6):976-80.

19. Dulloo P, Vedi N, Gandotra A. Impact of horizontal and vertical integration: Learning and perception in first-year Medical students. Natl J Physiol Pharm Pharmacol. 2017;7(11):11701176.

20. Vidic B, Weitlauf HM,Horizontal and vertical integration of academic disciplines in the medical school curriculum. Clinical Anatomy. 2002;15(3):233-235.

21. Harden RM. What is a spiral curriculum? Medical Teacher. 1999; 21(2):141-143 